\title{
HISTORIADORES E TEXTO LITERÁRIO: ALGUNS APONTAMENTOS
}

\author{
Historians and the literary text: some notes
}

Márcia Regina Capelari Naxara*

\begin{abstract}
RESUMO
Neste artigo procuro desenvolver algumas reflexões a propósito do trabalho do historiador com o texto literário, relação tecida de longa data, tendo em vista a narrativa como princípio comum, além do compartilhamento de categorias importantes para a construção do pensamento e da imaginação. Tomando "tempo" e "lugar” como elementos constitutivos, inerentes e imprescindíveis ao surgimento e afirmação do romance como gênero literário e, simultaneamente, ao campo da história como disciplina, procuro circunscrever aspectos da produção literária e historiográfica sobre o Brasil do século XIX, tendo em vista a preocupação marcante naquele momento com a apreensão da realidade por meio da verossimilhança e da veracidade, ou mesmo da ambição de verdade.
\end{abstract}

Palavras-chave: história e literatura; tempo e lugar; narrativa; verossimilhança; veracidade.

\begin{abstract}
This paper develops some reflections on how history works with literary texts. This has been a long time relationship, since both have narrative as a common principle and share important categories to build thought and imagination. The text assumes "time" and "place" are constitutive elements, inherent and necessary to the emergence and affirmation of romance as a literary genre and, simultaneously, of the field of history as a discipline. It then attempts to circumscribe some aspects of the literary and historiographic production on the $19^{\text {th }}$ century Brazil, bearing
\end{abstract}

* Departamento de História - Unesp-Franca. 
in mind the significant concern, at that time, to seize reality through likelihood and veracity, or even ambition for truth.

Key-words: history and literature; time and place; narrative; likelihood; veracity.

As reflexões desenvolvidas neste texto foram desencadeadas pela proposta de pensar o "lugar" ou "lugares" a partir de onde se enunciam teorias e concepções de mundo, ou melhor, de apreensão, compreensão, interpretação e criação de mundo(s) em diferentes lugares e, também, tempos. ${ }^{1}$ Questão que instigou considerar as aproximações mais que fronteiriças entre história e literatura, que de longa data compartilham a narrativa e o contar, escrever e descrever, ou melhor, (re)construir e (re)interpretar por meio da escrita, eventos "reais" e/ou "imaginários", na perspectiva da garantia do seu registro e perpetuidade, em especial quando considerados dignos de memória; narrativas estreitamente ligadas à dupla capacidade da escrita de cristalizar e, simultaneamente, dar vida às idéias e sentimentos a serem compartilhados; e à palavra e nomeação como instrumentos primordiais de partilha e vivência comum entre os homens e destes com o mundo que os cerca.

Tomando em consideração essa relação de longa duração me detenho no Brasil do século XIX para a elaboração de alguns apontamentos caros aos dois campos. ${ }^{2}$ Período relativamente longo (até porque grande parte de suas preocupações tiveram início no final do século XVIII e adentraram o XX, chegando mesmo aos dias atuais), em que foi marcante a preocupação com a apreensão da realidade, por meio da verossimilhança e da veracidade, ou mesmo, da ambição de verdade. Provavelmente, mais do

1 A proposição partiu de Joana Muylaert de Araújo ao coordenar o Grupo Temático “As teorias e seus lugares de enunciação”, por ocasião do Encontro Regional da ABRALIC 2005. Agradeço as leituras de Jacy Seixas e Virgínia Camilotti.

2 As reflexões aqui desenvolvidas ancoram-se, em grande parte, em Cientificismo e sensibilidade romântica em busca de um sentido explicativo para o Brasil no século XIX. Brasília: Universidade de Brasília, 2004. 
que descrever e relatar, tratava-se, naquele momento, de descobrir, criar e interpretar o Brasil; processo que foi perseguido simultaneamente pela, ainda bastante recente e amadora, história/ historiografia (verdade/ veracidade) e, penso que de forma mais consistente pela, também nova, literatura (verossimilhança/ veracidade). Se consideramos literatura e história como tendo produzido interpretações fundadoras e fundantes sobre o Brasil, verificamos que a história bebeu nos recursos da narratividade literária, aproximando-se ora do rigor de verdade científica, ora do ensaio, com bases fortemente cientificistas; e que a literatura alimentou-se da história para a composição do romance, em especial o histórico, assim como a poesia, principalmente quando de caráter épico. Os dois campos tendo como foco de preocupação a compreensão dos homens na sua relação com a natureza e entre si, suas formas de expressão culturais, suas instituições, organização e visões de mundo, com acento maior ou menor no recorte nacional. Desse amálgama resultaram as diferentes e simultaneamente aproximadas interpretações do Brasil, num movimento e oscilar constantes entre seduções e armadilhas, tanto da razão como da sensibilidade, razão pela qual resulta uma autocompreensão e auto-imagem, pelo colocar-se no mundo de forma objetiva e apresentada como racional; sensibilidade pela imaginação, valores e vertentes de significação simbólica, presos ao domínio dos sentidos, sentimentos e sensações. Domínios estes construídos, também, pela ambição de compreender - razão e sensibilidade - racionalmente.

Literatura/ romance e história/ historicismo, ambos herdeiros e contrapostos ao peso inaugural do iluminismo, em movimento que procurou conciliar razão e mundo sensível, na reação ao universalismo e à propositura de uma razão/ história universal/ cosmopolita, pela elaboração de histórias particulares das nações, dos povos e das nacionalidades. Por um lado o romance e por outro o movimento da história, defendendo a temporalização e historicização dos eventos, com a definição precisa de meio, tempo e lugar como elementos constitutivos das ações e relações entre os homens. O subjetivismo e a individuação como características básicas do romance, em reação aos universais, que independem de tempo e espaço. E também a dimensão "original”3 da experiência individualizada

3 WATT, Ian. (1957) A ascensão do romance - estudos sobre Defoe, Richardson e Fielding. Tradução: Hildegard Feist. São Paulo: Cia. das Letras, 1996. p.16. O autor chama a atenção para a mudança de significado da palavra "original” que passou de "o que existiu desde o início” na Idade Média para o "não derivado, independente, de primeira mão” no século XVIII. 
do que é contado na narrativa e de como a narrativa é construída para contar o enredo ficcional.

“Tempo" e "lugar” são tomados, aqui, como elementos instituintes, inerentes e imprescindíveis ao surgimento e afirmação do romance como gênero literário e, simultaneamente, ao campo da história como disciplina. Consideramos que boa parte do romance, no século XIX, enveredou para a história ou para o que poderíamos chamar historicização de paisagens e personagens como grau de aferição de verossimilhança e de afirmação do indivíduo como ser histórico -,e portador de subjetividade, possibilitando aproximar concepções como as de "romance de formação" (Bildungsroman), incluindo a ficção e as narrativas de viagem, e "história mestra da vida", em momentos em que foi crucial pensar a nação e, mais que isso, pensá-la por meio de suas instituições e manifestações criativas, artes e, no caso das letras - língua, literatura e história, na realização da idéia de que no Romantismo "tudo se faz história" e a história -, se faz "realidade”, como bem afirmou Jacó Guinsburg. ${ }^{4}$ De um outro ponto de vista, também aproximado, ao avaliar a importância da noção de formação na psicanálise, bem como sua estreita relação com o romance, Christian Dunker aponta a força da idéia de formação (Bildung) no romantismo alemão, aproximando-a da experimentação e da imagem recorrente a "uma espécie de viagem ou de jornada em que a experiência do caminho percorrido é tão ou mais importante que o destino final”; alude ao seu emprego simultâneo a processos individuais e ao processo histórico, na medida em que é utilizado “também para designar o processo histórico de formação de uma nação, de uma língua ou de uma comunidade a partir de uma origem, destino ou sentido comum". ${ }^{5}$

Processos em que ganham importância os elementos identitários, capazes de tocar a sensibilidade e conjugar o sentimento de pertencimento a algo maior, que remete para o todo orgânico, sem o qual o singular não tem como ganhar existência. Formação tomada como componente central da sensibilidade do intelectual/ artista romântico, que vê a si mesmo e se coloca como indivíduo que, imbuído de um dever de missão, esclarece e ilumina o mundo aos demais. Formação, insisto, como processo, em que se acentua o

4 GUINSBURG, Jacó. (1978) Romantismo, historicismo e história. In: O romantismo. São Paulo: Perspectiva, 1985. p.18.

5 DUNKER, Christian I. L. O romance de formação do analista. Revista Viver Mente \& Cérebro. Coleção Memória da Psicanálise, São Paulo, n. 4 (Lacan), p. 64-73, 2005. Citação: p. 65. 
caminho percorrido e a percorrer e que se concretiza no tempo ou, mais precisamente, na duração. Aproxima-se dessa forma, no romance e na história no decorrer do século XIX, a temporalidade como o lugar de construção, transformação e solidificação dos elementos, tanto identitários como de alteridade, caros à formação de grupos, associações e nações. Processo que, no fundo, não está destinado a se completar - na verdade jamais se completa - pois a sua completude o anularia, absorvendo-o num ponto final - incompatível com a própria idéia de história, movimento incessante e permanente.

Poetas e prosadores dedicaram-se à tarefa de procurar estabelecer origens e demarcar momentos e acontecimentos que esclarecessem, delimitassem e concretizassem a existência da nação - ou melhor, das nações procurando captar a sua personalidade coletiva ou seu espírito nacional. Procura realizada pelo estudo dos textos antigos, dos mores e falares, do registro dos mais variados aspectos de sua cultura, tanto oral como escrita e representativa dos seus variados habitantes, procurando uma unidade identitária, garantidora da coesão social. Visualizava-se a impossibilidade de procurar uma genealogia e apreender a alma de um povo somente pela razão sem o sentimento e a intuição. Busca que foi realizada também no Brasil, num esforço de definição e delimitação de origens características e autênticas, portadoras de brasilidade, que não pudessem ser confundidas ou dissolvidas em outra; ou seja, uma genealogia que fosse capaz de estabelecer a aproximação a uma origem mítica sobre a qual se construiria a nacionalidade - a busca da elaboração de textos fundadores, que pudessem conter significado semelhante ao demarcado pelo Nibelungenlied ${ }^{6}$ para a genealogia alemã, como aponta Flora Sussekind em estudo em que procurou recuperar várias das tentativas realizadas por românticos brasileiros de, por meio da literatura e da língua, de forma original, buscar a realização de poemas e textos fundadores da nacionalidade.

6 Entre outras indicações, Flora Süssekind assinala a primeira edição crítica do Nibelungenlied em 1826, e uma segunda em 1827; a Chanson de Roland foi seguidamente editada em 1836 e 1837. Ibid., p. 480 .

7 Flora Süssekind reúne algumas das tentativas realizadas por diversos autores — José de Alencar, Gonçalves de Magalhães, Sousândrade, Fagundes Varela — para alcançar a forma de um poema nacional, épico, que definisse heróis ancestrais num texto fundador. O escritor como genealogista: a função da literatura e a língua literária no romantismo brasileiro. In: PIZARRO, Ana (Org.). América Latina: palavra, literatura e cultura. v. 2. Emancipação do discurso. São Paulo: Memorial; Campinas: Unicamp, 1994. p. 480-482. 
O romance de "formação" e de "fundação" inaugurou, portanto, uma linha de interpretação que buscou dotar a nação não somente de mitos fundadores, mas reter hábitos, costumes, vivências, história. História que também foi pensada - na tentativa de união entre objetividade e sensibilidade - por uma historiografia, como já apontado, nascente. Gêneros fundadores que, nas formas de poesia, romance, ensaio e historiografia, procuraram, cada um a seu modo e, num compartilhar simultâneo, produzir o que, no dizer de Willi Bolle, alcançou sua máxima expressão com Guimarães Rosa. Em grandesertão. $b r^{8}$ o autor assinala a existência de uma longa tradição literária e historiográfica de produção de "retratos do Brasil" (expressão remetida a Paulo Prado) desde o século precedente; Grande Sertão: Veredas, que do seu ponto de vista reconstrói Os Sertões, sintetizaria essa busca incessante promovendo, no entanto, uma guinada no enfrentamento da questão. ${ }^{9}$ Ao recompor em mapas os espaços e paisagens das duas obras, Bolle remete para ambos os "sertões" (Euclides e Guimarães) e para as "veredas" - caminhos -, a busca do estabelecimento de temporalidades e contrastes sociais capazes de conter tanto o passado como o futuro. Seu trabalho coloca em "interação" duas grandes leituras e representações da nação e da nacionalidade, aproximando de forma exemplar história e literatura na sensibilidade necessária para se pensar o Brasil e seus contrastes, em especial sociais, ao que parece difíceis de conciliar e de enfrentar. Para o autor, no entanto, Grande Sertão não encerra nem fecha a busca incessante de quem somos e como nos reconhecemos como Brasil, questão que, ao que tudo indica, permanece em aberto, assim como o diálogo e o contínuo estar em formação.

Partindo de premissas outras e também procurando significados para a compreensão de uma "tradição" de conhecimento do Brasil que aproxima razão e sensibilidade, Stella Bresciani, em $O$ charme da ciência e a

8 Ver, em especial, o Prefácio. BOLLE, Willi. grandesertão.br: o romance de formação do Brasil. São Paulo: Duas Cidades; Editora 34, 2004.

9 Para o autor, a questão primordial do Brasil, definida já no início do primeiro capítulo, “é a ausência de um verdadeiro diálogo entre os donos do poder e o povo que caracteriza também a nossa época, constituindo-se num sério entrave para a plena emancipação do país”. Ibid., p. 17. 
sedução da objetividade, ${ }^{10}$ nos mostra o quanto esse movimento se sustenta a partir da construção histórica de "lugares comuns", tornados elementos constitutivos e instituintes das numerosas interpretações do Brasil ao longo dos séculos XIX e XX; "lugares comuns" passíveis de prender história e literatura na armadilha de estar a retomar incessante e repetitivamente 0 passado colonial brasileiro e sua "formação primeira", em busca de respostas a questões que acabam por constituir um fundo comum que se esgota no próprio questionamento - busca-se nos "males de origem", para utilizar uma outra expressão comum, a explicação para os "males" do presente: colonização portuguesa e formação racial alcançando postos privilegiados, ao lado de uma natureza avaliada sempre, de forma ambivalente, como portadora de uma grandiosidade que, por excessiva, ora é positivada como elemento de sedução, ora detratada como impossibilitadora de civilização.

\section{III}

Voltando ao século XIX, procurei tomar o momento em que foram gestados alguns dos primeiros modelos de interpretação e em que foram realizados esforços para dotar de sentido, criando, a história da pátria que então nascia e se formava. A história, na perspectiva de preencher o papel de "mestra da vida", por meio do modelo elaborado por Martius, premiado e adotado pelo IHGB (também nascente), pontuou os elementos necessários a essa constituição e construção de sentido. Literatos e historiadores colocaram-se, portanto, à procura de um Brasil que se queria "ver”, "sentir”, “conhecer”, “dar a ver”, “objetivar” e "prescrever”, já com os olhos postos no futuro. Processo marcante, que se instalou com a vinda da Corte portuguesa, verdadeiro momento de inflexão, ${ }^{11}$ marcado pela procura de caminhos capazes de colocar o Brasil na senda da civilização, num processo em que as letras ganhariam lugar de destaque.

10 BRESCIANI, M. Stella. O charme da ciência e a sedução da objetividade: Oliveira Vianna entre intérpretes do Brasil. São Paulo: Unesp, 2005.

11 Ver FRANÇA, Jean Marcel Carvalho. Literatura e sociedade no Rio de Janeiro oitocentista. Lisboa: Casa da Moeda/ Imprensa Nacional, 1999. 
Memória, história e literatura foram aproximados no que se considerava verdadeira missão para a construção e condução da nação. O plano de Martius propôs a criação de um Brasil, no plano da História, que deveria partir da descrição da sua natureza, a que se incorporaria a formação do povo a partir das três raças originárias: brancos, negros e índios. Plano em que os indígenas colaborariam para alimentar lendas de origem (mitos fundadores, portanto); os negros apareceriam de forma secundária, por constituírem elementos dificultadores do processo civilizatório (em maior escala que o indígena); brancos como portadores da civilização, processo a ter continuidade em sua implementação pela monarquia (forma ideal de governo). A história do Brasil analisada como ramo da história de Portugal e dos portugueses/ Europa. Recomendou, ainda, a demarcação dos eventos que pudessem ser considerados caros à formação da nacionalidade, ${ }^{12}$ constituindo marcas indeléveis do processo histórico de formação e esclarecimento, capaz de gerar e tornar sólidas as bases sobre as quais se erigia, então, a nação. Alencar, por seu lado, viu a formação da literatura brasileira como um processo orgânico e evolutivo que se encontrava em andamento e que produziria o amálgama que daria origem, no futuro, a um Brasil original e autêntico. Paralelizava sua produção literária ao movimento de nascimento e desenvolvimento do país: na primeira fase, primitiva ou aborígine, localizada no limiar e confluência entre história e mito, localizou Iracema, romance em que retoma lendas e mitos dos povos selvagens, autóctones, colocando-os em contato com o português colonizador, no que representaria um primeiro contato para a formação da futura nacionalidade; na segunda, período já histórico, teria ocorrido o "consórcio do povo invasor com a terra americana”, ${ }^{13}$ ou seja, o encontro mais efetivo entre a velha Europa e a jovem América, momento de amalgamento entre cultura e natureza, que fornece rico material para o romance histórico, visível em O guarani e As minas de prata. A independência política marcaria o início da terceira fase, em que Alencar localiza a infância da literatura brasileira, momento em que, esperava, viesse a se formar o "verdadeiro gosto nacional”, com uma efetiva assimilação da civilização e com a mescla dos dois elementos -

12 A propósito, ver GUIMARÃES, Manoel Luís Salgado. Nação e civilização nos trópicos: o instituto histórico e geográfico brasileiro e o projeto de uma história nacional. Estudos Históricos, Rio de Janeiro, n. 1 (Caminhos da historiografia), p. 5-27, 1988.

13 ALENCAR, José de. Bênção paterna, prefácio a Sonhos d'Ouro. São Paulo, 1872. p. 11. 
natureza selvagem e civilização. Mesmo que o processo não fosse simultâneo em todo o território e a civilização adentrasse irregularmente, percebendo-se a permanência de aspectos de selvageria em muitos recantos do país e mesmo nas grandes cidades, gradativamente, com o passar do tempo, a "cor local" e a originalidade que se construía ganhava e continuava a ganhar espaço e visibilidade. Nos centros urbanos reconheceu o movimento para se adentrar uma adolescência literária, "especialmente na corte, a sociedade tem a fisionomia indecisa, vaga e múltipla, tão natural à idade da adolescência. É o efeito da transição que se opera, e também do amálgama de elementos diversos". ${ }^{14}$ Uma evolução, portanto, da natureza para a civilização, da floresta/ campo/ sertão para a cidade/ civilização. Importante demarcar a ênfase alencariana na idéia da formação do novo - a Europa/ Velho Mundo poderia recuperar-se, renovar-se e rejuvenescer no contato com a América/ Novo Mundo. Não se tratava, para Alencar, de uma justaposição, mas do surgimento de uma nova sociedade, original e singular em sua existência - tempo, espaço e paisagem considerados como elementos naturalmente essenciais à narrativa e ao desenvolvimento do enredo e, por que não, da história.

De um lado a constituição de um saber científico, objetivo, perpassado por uma forte sensibilidade romântica e, de outro, a estética e o conhecimento românticos ambicionando a constituição de um saber capaz de explicar o mundo, de apreender a(s) sensibilidade(s) característica(s) dos homens com relação ao mundo, a si mesmos e à natureza em que vivem, como “uma dimensão da realidade humana”. ${ }^{15}$ Uma cultura romântica que procurou colocar em questão a "situação global do homem no Universo", ${ }_{16}^{16}$ a possibilidade da compreensão de si mesmo, da sua posição, simultaneamente, em relação a Deus, ao mundo e à história. Movimento que procurou visualizar o indivíduo (personagem/ leitor) num cenário, num local, numa paisagem, no tempo enfim: ambicionou "colocar o homem inteiramente em seu cenário físico”, ${ }^{17}$ recorrendo à memória e ao que já foi produzido, num

14 Ibid., p. 11.

15 GUSDORF, Georges. (1982-83) Prefácio. In: Le romantisme: I - Le savoir romantique. Paris: Payot \& Rivages, 1993. p. 8.

16 Ibid., p. 8.

17 TATE, Allen. Techniques of fiction. In: ALDRIDGE, J. W. (Ed.). Critiques and essays on modern fiction, 1920-1951. New York, 1952. p. 41. apud WATT, Ian, op. cit., p. 27. 
esforço de verossimilhança ou da criação do novo a partir do (re)arranjo de elementos conhecidos, na tentativa de produzir algo que fosse, ao mesmo tempo, inédito - original — e verossímil. Algo capaz de tocar, além da razão, os sentidos, os sentimentos e a alma. A verossimilhança aparecendo como elemento que carrega em si a perspectiva do que o romance possa ensinar e provocar, tanto pela eficácia na transmissão de valores e visões de mundo que o tornam atraente com relação à educação ética e moral, como pela sedimentação dos ensinamentos, por trabalhar com o que é interior aos homens, ou seja, suas paixões e sentimentos. No caso, história e literatura, além de outros campos das manifestações dos homens, colaborando para a formação do sentido patriótico caro à pátria e à nação.

O romancista, em especial o que produz romance histórico, freqüentemente busca nas crônicas e na história o suporte para a ambientação dos personagens e sustentação do enredo, de forma a torná-lo verossímil, mesmo quando cria e trabalha a figura do herói. Em Alencar tal proposta fica claramente explicitada pelo próprio autor, em notas finais, de forma a contribuir para reforçar a verossimilhança e procurar um caráter de veracidade entre real e imaginário, aproximando-os. Respaldado na lenda ou na crônica, favorece a compreensão dos sentimentos e ações dos personagens que constrói, conferindo-lhes maior credibilidade.

\section{IV}

Do contato com a diversidade de textos que procuraram compreender e dar a compreender o Brasil assomam questões relacionadas à alteridade que considero fundamentais. Questões que foram e são determinantes do(s) lugar(es) a partir de onde se elaboraram e enunciaram interpretações que vieram a constituir "lugares comuns", "retratos do Brasil", ou interpretações de "formação" e "fundantes”, com permanência e longa duração. A contraposição “civilização/ barbárie” imperou no século XIX, tendo sido tomada como ponto de partida para as demais dicotomias, utilizada e apresentada como verdadeira nos argumentos pelos quais foram procuradas explicações para o processo histórico. Dicotomia inicial que, com todas as suas derivadas, proporcionou leituras do Brasil elaboradas a partir do pólo 
reconhecido como "civilizado", de forma a se pensar o Brasil predominantemente, embora não de forma absoluta, pela ausência, pela falta, pelo que não existia e precisava ser elaborado, desenvolvido ou conquistado. Anseio de civilização que projetou e projeta o olhar, e se espelha fora (na direção do modelo desejado), vendo no Brasil somente o atraso, a negação - avaliação que ganha foros de verdade se lembramos que o século XIX, em especial na sua segunda metade, esteve imbuído da idéia de sucessão evolucionista e de crença no progresso. Nesse sentido, acentuou-se o avesso - lugar em que se colocava o Brasil - lido como atraso e como impossibilidade. Acentuou-se, portanto, a avaliação pautada pela ausência, como afirmado logo acima, e não pela diferença e diversidade.

O distanciamento entre os pólos dicotômicos possibilitou pensar, também, não somente o inconciliável entre os pontos extremos, por mais que a aproximação fosse desejada, mas aquele existente entre as instituições (em especial políticas) e a realidade social, permitindo apontar limites à concretização de teorias e práticas que, gestadas em outro "lugar”, não se adequariam ao solo nacional; de modo similar, a criação/ criatividade, as idéias, teorias e "modismos" também desembarcavam já prontas, chegadas de "fora”, produzidas nos ambientes civilizados, cabendo a nós, brasileiros, limitarmo-nos a cópias e imitações quase sempre imperfeitas.

Tempo e lugar, portanto, como elementos imprescindíveis e associados para pensar as idéias e teorias, gestadas e manifestadas em atos e produções concretos, capazes de estabelecer marcos e delimitar fronteiras (nem sempre sólidas) entre $\mathbf{o}$ antes e $\mathbf{o}$ depois e entre o lugar e $\mathrm{o}$ não lugar ou fora do lugar. Barreiras interpostas, também, entre o conhecido e o estranho, entre o nós e o(s) outro(s). Sentidos em que algumas questões sobressaem e causam (ainda) inquietações; inquietações relacionadas à compreensão do século XIX e, mais especificamente, às leituras realizadas sobre o Brasil - sua história e produção literária - no período, que vêm tendo longa duração e efetividade. Concepções que conduziram a pensar e imaginar o mundo de forma maniqueísta (ocidente e ocidentalização), pela contraposição civilização e barbárie ou pela dualidade cosmopolitismo e localismo, ainda não desconstruída, conduzindo ao que parece um beco sem saída.

Se retomamos o princípio inicial da "formação", em que se acentua o processo e não a sua finalidade, o que poderia ser um componente positivo transforma-se, também, em negatividade. Nega-se ou problematiza- 
se o presente pela ênfase na "falta” e projeta-se no (e não o) futuro como possibilidade de um Brasil em formação infinda - sempre e eternamente potencial - a caminho de uma grandiosidade que se revela rica em retórica discursiva, num movimento histórico temporalizado, em que se lê o presente como mundo desencantado. 